Case Study

\title{
The effect of shoulder supporting banding and shoulder pulling banding using elastic bands on shoulder pain and scapular position of a scapular dyskinesis patient with shoulder depression and scapular downward rotation
}

\author{
WON-GYU Yoo ${ }^{1)}$ \\ 1) Department of Physical Therapy, College of Biomedical Science and Engineering, Inje University: \\ 607 Obang-dong, Gimhae, Gyeongsangnam-do 621-749, Republic of Korea
}

\begin{abstract}
Purpose] This study developed methods of shoulder supporting banding and shoulder pulling banding using elastic bands for scapular dyskinesis patients with shoulder depression and scapular downward rotation and investigated the effect on shoulder pain and scapular position. [Subject] The subject was a scapular dyskinesis patient with shoulder depression and scapular downward rotation and shoulder pain. [Methods] This study compared the scapular position and upper trapezius pressure pain between before and after applying the shoulder supporting banding and shoulder pulling banding for one month. [Results] The results showed that the acromion depression distance and scapular inferior downward distance decreased and that the pressure pain threshold of the upper trapezius increased after using shoulder supporting banding and shoulder pulling banding for one month. [Conclusion] Therefore, the shoulder banding methods using elastic bands showed positive effect in a scapular dyskinesis patient with shoulder depression and scapular downward rotation.

Key words: Elastic band, Scapular dyskinesis, Shoulder pain
\end{abstract}

(This article was submitted Sep. 14, 2015, and was accepted Oct. 31, 2015)

\section{INTRODUCTION}

As a risk factor for work-related musculoskeletal disorders related to sedentary work, prolonged poor postures such as forward head and protracted shoulder postures could contribute to the prevalence of neck and shoulder pain ${ }^{1)}$. Wegner et al. ${ }^{2}$ suggested that a postural correction strategy for scapular position was helpful for restoring muscular activation in patients with neck pain. Dyskinesis of the scapula can be identified visually with the scapular dyskinesis test, which includes dynamic loaded tasks ${ }^{3}$. The scapular dyskinesis test has been validated in terms of altered scapular kinematics using a three-dimensional motion capture system ${ }^{3,4)}$. Several studies have reported about scapular kinematics and dyskinesis ${ }^{3,4)}$. Recent findings suggested that postural correction focusing on scapular alignment is an effective way of reducing neck and shoulder pain ${ }^{2}$. Also, the scapular position data suggested that the muscular length of upper trapezius was overstretched. A study has also been performed to investigate the pressure pain threshold of the upper trapezius in a subject with scapular and shoulder depression ${ }^{5)}$. In another report, the overstretched upper trapezius showed increased pain sensitivity compared with the control ${ }^{6}$. So, the present study developed methods of shoulder supporting banding and shoulder pulling banding using elastic bands for scapular dyskinesis patients with shoulder depression and scapular downward rotation and investigated the effect on shoulder pain and scapular position. 


\section{SUBJECT AND METHODS}

The subject was a 32-year-old male scapular dyskinesis patient with shoulder depression, scapular downward rotation, and shoulder pain and no specific surgical or medical history of the shoulder. The subject received an explanation about the purpose and methods of the study prior to participation and provided informed consent according to the ethical principles of the Declaration of Helsinki. He had experienced severe tenderness of the right upper trapezius for 1 month when working with his right hand and during long periods of computer work. However, he did not undergo any particular treatment. The result of the initial scapular dyskinesis test showed that the right scapula was rotated downwardly and that the right shoulder was totally depressed. An algometer was used to determine the amount of pressure applied to the participant by the therapist. A dolorimeter (Fabrication Enterprises, White Plains, NY, USA) pressure algometer was used to measure pressure pain. The dolorimeter consisted of a metal probe that could measure pressures up to $20 \mathrm{lb}$ in $0.25 \mathrm{lb}$ increments, respectively. The pressure pain threshold (PPT) represents the amount of pressure needed for the first sensation of pain. The subject was asked to say "stop" when the sensation changed from pressure to pain. The PPT was measured $2 \mathrm{~cm}$ lateral to the location of the upper trapezius EMG attachment site. A palpation meter (PALM; Performance Attainment Associates, St. Paul, MN, USA) was used to measure the distance and inclination between two bony landmarks of the body. The PALM consisted of an inclinometer and two caliper arms, and the inclinometer had a semicircular arc that moved within the range of $0-30^{\circ}$ in either direction from the midline at $1^{\circ}$ intervals. The PALM was used as a special body-tool interface to combine the advantages of palpation with the objectivity and reliability of caliper and inclinometer measurements. In a previous study, the scapular measurement reliability of the PALM was investigated by measuring the distance from the inferior angle to the thoracic spine and the acromion depression. The same method was used in the present study; the horizontal distance from the inferior angle of the scapula to the spinal process and the vertical depression of the acromion were used to identify the scapular position. The acromial depression was determined using the PALM calculator, which combined the values for distance and inclination between the acromion and the $\mathrm{C} 7$ spinous process. The horizontal distance from the inferior angle to the spinal process was defined as follows: one arm of the caliper was fixed at the inferior angle of the scapula and the other arm was positioned at the spinal process such that the inclinometer indicated $0^{\circ}$. A Thera-Band elastic band of proper strength was selected for the patient by a therapist on the basis of the Thera-Band resistance levels (indicated by color): black $>$ sliver $>$ blue $>$ green $>$ red $>$ yellow. A blue Thera-Band was selected for the subject, and it was applied as follows. For shoulder supporting banding, one end of the elastic band was tied frontally on the left shoulder, and the other end of the elastic band was passed under the right axillae, passed behind the back, and again tied on the left shoulder. The shoulder supporting banding provided support for the depressed shoulder. The second, shoulder pulling banding, this is worn similar model with wearing braces, the subject was worn the pelvic belt connected with both ends of the rolled elastic band (vertical is the end). The rolled elastic band passed the scapular superior angle. For this, assistance band is connected with shoulder supporting banding in behind the back. The shoulder pulling banding provided scapular upward rotation via its own force combined with that provided by the shoulder supporting banding. The subject applied these bandings for 1 month when working with his right hand and during long periods of computer work. This study compared the scapular position and upper trapezius pressure pain between before and after applying these bandings.

\section{RESULTS}

The vertical distance from $\mathrm{C} 7$ to the acromion was $8.4 \mathrm{~cm}$ initially, and $7.1 \mathrm{~cm}$ after using shoulder supporting banding and shoulder pulling banding for one month. The horizontal distance from the inferior angle to the horizontal level of the spinal process was $5.1 \mathrm{~cm}$ initially, and $6.8 \mathrm{~cm}$ after using shoulder supporting banding and shoulder pulling banding for one month. The pressure pain threshold of the upper trapezius was $8.5 \mathrm{~kg}$ initially, and $11.0 \mathrm{~kg}$ after using shoulder supporting banding and shoulder pulling banding for one month.

\section{DISCUSSION}

This study developed methods of shoulder supporting banding and shoulder pulling banding using elastic bands for scapular dyskinesis patients with shoulder depression and scapular downward rotation and investigated the effect on shoulder pain and scapular position. The results showed that the acromion depression distance and scapular inferior downward distance decreased and that the pressure pain threshold of the upper trapezius increased after using shoulder supporting banding and shoulder pulling banding for one month. The most important treatment for scapular depression syndrome is passive support of the scapula ${ }^{5,6}$. A depressed scapular position is related to a decreased pressure pain threshold in the upper trapezius region ${ }^{5,6}$. Weakness of the upper trapezius causes the scapula to rest in a downwardly rotated position as a result of the unopposed effect of gravity on $\mathrm{it}^{7}$ ). Although the relationship between alignment and pain is still unclear, alignment is one of numerous factors contributing to the development of mechanical pain ${ }^{5}$. Elevating the scapula passively during upper extremity activities in subjects with depressed shoulders is an effective method for reducing trapezius symptoms and neck pain $^{6}$. When abduction of the arm is attempted, the middle and posterior fibers of the activated deltoid-unopposed by the 
upper trapezius-will act on the lighter scapular to increase the downward rotary pull on the scapula. The Thera-Band, which provides varied resistance through the range of movement, has been used for rehabilitation in combination with therapeutic exercise $^{8,9)}$. It is light and portable, has low resistance, and can be adjusted to accommodate various situations ${ }^{8,9)}$. The Thera-Band is also easy and simple to apply, and it is inexpensive. I thought that the shoulder supporting banding would provide support to the depressed shoulder and that the shoulder pulling banding would provide scapular upward rotation via its own force combined with that provided by the shoulder supporting banding. The present study showed that the shoulder banding methods using elastic bands had positive effects on the scapular dyskinesis patient with shoulder depression and scapular downward rotation.

\section{REFERENCES}

1) Ranasinghe P, Perera YS, Lamabadusuriya DA, et al.: Work related complaints of neck, shoulder and arm among computer office workers: a cross-sectional evaluation of prevalence and risk factors in a developing country. Environ Health, 2011, 10: 70. [Medline] [CrossRef]

2) Wegner S, Jull G, O'Leary S, et al.: The effect of a scapular postural correction strategy on trapezius activity in patients with neck pain. Man Ther, 2010, 15: 562-566. [Medline] [CrossRef]

3) McClure P, Tate AR, Kareha S, et al.: A clinical method for identifying scapular dyskinesis, part 1: reliability. J Athl Train, 2009, 44: 160-164. [Medline] [CrossRef]

4) Uhl TL, Kibler WB, Gecewich B, et al.: Evaluation of clinical assessment methods for scapular dyskinesis. Arthroscopy, 2009, 25: 1240-1248. [Medline] [CrossRef]

5) Sahrmann SA: Diagnosis and treatment of movement impairment syndromes. St Louis: Mosby, 2002.

6) Azevedo DC, de Lima Pires T, de Souza Andrade F, et al.: Influence of scapular position on the pressure pain threshold of the upper trapezius muscle region. Eur J Pain, 2008, 12: 226-232. [Medline] [CrossRef]

7) Levangie PK, Norkin CC: Joint Structure and Function: A Comprehensive Analysis, 5th ed. Philadelphia: F.A. Davis Company, 2005.

8) Findley BW: Training with rubber bands. Strength Condit J, 2004, 26: 68-69. [CrossRef]

9) Yoo IG, Yoo WG: The effect of a new neck support tying method using thera-band on cervical ROM and Shoulder muscle pain after overhead work. J Phys Ther Sci, 2013, 25: 843-844. [Medline] [CrossRef] 